\title{
Aproximación al patrón de normalidad de TSH para la población chilena según Encuesta Nacional de Salud 2009-2010
}

\author{
LORENA MOSSO ${ }^{1}$, PAULA MARGOZZINI², \\ PAMELA TREJO ${ }^{1}$, ANGÉLICA DOMÍNGUEZ ${ }^{2}$, SANDRA SOLARI ${ }^{3}$, \\ GONZALO VALDIVIA ${ }^{2}$, EUGENIO ARTEAGA ${ }^{1}$
}

\section{Thyroid stimulating hormone reference values derived from the 2009-2010 Chilean National Health Survey}

Background: The determination of thyroid stimulating hormone (TSH) reference values is critical for the diagnosis of thyroid diseases. Aim: To explore and discuss different definitions to establish TSH reference values using a Chilean national survey sample. Material and Methods: The 2009-2010 Chilean National Health Survey recruited 5,416 participants between the ages of 15 and 96 years, from all geographic regions of Chile, including urban and rural zones. TSH was measured in a random subsample of 2,785 adults. Median value, 2.5 and 97.5 percentiles were described in three different populations: total survey population, "disease-free population" and the "laboratory kit disease free population". Results: TSH values were higher among women, the elderly and the less educated population. The 97.5 percentile value in the disease-free population was $7.46 \mathrm{uUI} / \mathrm{ml}$. Using this value as a cut-off, hypothyroidism prevalence would be $4.8 \%$ in Chile and estimated pharmacological treatment coverage would be $58 \%$. When laboratory kit cut-offs are used, prevalence rises to $22 \%$ and treatment coverage drops to $12 \%$. The 2.5 percentile value in the disease-free population was $0.83 \mathrm{uUI} / \mathrm{ml}$, which yields an estimated hyperthyroidism prevalence of $3.89 \%$. Conclusions: Median TSH concentration values in the Chilean "disease-free population" are higher than those proposed by laboratory kits and those of developed countries. TSH values in the general population of Chile are also higher in women, the elderly and the less educated population.

(Rev Med Chile 2013; 141: 95-103).

Key words: Hypothyroidism; Thyroid gland; Thyrotropin.

\author{
Escuela de Medicina. \\ Pontificia Universidad \\ Católica de Chile. \\ 'Departamento de \\ Endocrinología. \\ ${ }^{2}$ Departamento de Salud \\ Pública. \\ ${ }^{3}$ Laboratorios Clínicos. \\ Financiamiento: La \\ Encuesta Nacional de \\ Salud fue financiada por \\ el Ministerio de Salud de \\ Chile; las determinaciones \\ de TSH fueron financiadas \\ por la Pontificia \\ Universidad Católica de \\ Chile, y por un aporte \\ directo e irrestricto de \\ Laboratorio Merck S.A. \\ Recibido el 25 de abril de \\ 2012, aceptado el 8 de \\ noviembre de 2012 \\ Correspondencia a: \\ Dra. Lorena Mosso G. \\ Departamento de \\ Endocrinología \\ Escuela de Medicina, \\ Pontificia Universidad \\ Católica de Chile \\ Lira $85,5^{\circ}$ piso \\ Santiago-Chile \\ Teléfono: 56-02-354 3095 \\ Fax: 056-02-638 5675. \\ E-mail:mosso@med.puc.cl
}

$\mathrm{L}$

a determinación de los valores normales de distintos parámetros médicos es un tema de gran discusión a nivel mundial. El rango de referencia normal de TSH no escapa a lo anterior y es crítico a la hora de determinar el estado de salud tiroideo de los individuos ${ }^{1}$.

La mayor parte de los laboratorios clínicos utiliza rangos de normalidad basados en los valores entregados por el fabricante de kit, al cual se le exige, de acuerdo a normativas internacionales como la de la National Academy of Clinical Biochemistry (NACB), incluir al menos 120 sujetos sanos para dicha estandarización ${ }^{2}$. El punto en discusión es el criterio utilizado para definir un sujeto sano, en términos de selección de la población de referencia, y el número mínimo de sujetos a analizar para ser representativo de la población estudiada.

A nivel poblacional el tema es aún más controversial. Se ha recomendado que el mejor método para definir normalidad poblacional son las en- 
cuestas nacionales de salud. Existe acuerdo de considerar normal hasta el percentil 97,5 de los sujetos sanos de referencia ${ }^{2}$. La población de referencia de la encuesta nacional de salud norteamericana (NHANES), por ejemplo, se definió como aquella población libre de antecedentes de patología tiroidea, bocio, medicamentos que alteren la función tiroidea, anticuerpos anti tiroperoxidasa (AcTPO) e hipotiroidismo o hipertiroidismo bioquímico predefinido por laboratorio; este último punto es controversial dado que establece a priori un sesgo dado por el valor previo del $k i t^{3,4}$.

La Asociación Americana de Endocrinólogos Clínicos (AACE) planteó la necesidad de utilizar un rango más estrecho de normalidad de TSH $(0,3$ a 3,0 $\mu \mathrm{UI} / \mathrm{mL}$ ) privilegiando valores más cercanos a la media de la población sana. A su vez, la NACB, planteó en el año 2002 la necesidad de bajar el rango superior de normalidad de TSH a $2,5 \mu \mathrm{UI} / \mathrm{mL}$, correspondiente al percentil 95 de una población que consideran sana y que descarta aquellos con antecedentes personales y familiares de patología tiroidea, con AcTPO positivos y bocio palpable 2 .

Recientemente se ha planteado que también debiera excluirse de esta población a los que presenten alteraciones en el patrón ecográfico tiroideo, situación que haría más dificultosa la determinación de la normalidad poblacional ${ }^{5-7}$.

La discusión actual requiere de más estudios poblacionales que determinen la distribución normal de TSH en población general representativa. Hasta ahora los países en desarrollo como el nuestro han utilizado los valores entregados por los kits de laboratorio para definir normalidad de distintos parámetros. Estos kits han sido producidos en países con otras realidades sociodemográficas y de salud, y pueden no representar la nuestra.

Recientemente, se ha demostrado que los rangos de referencia de TSH de los laboratorios no reflejan necesariamente las diferencias existentes en edad, etnia, genética, influencias del ambiente y alimentación. Se ha planteado la necesidad de establecer rangos de referencia específicos para cada población y así evitar una clasificación errónea de un sujeto como enfermo o sano ${ }^{8-10}$. Un pequeño descenso del valor de corte TSH para definir hipotiroidismo sube en forma exponencial el diagnóstico de la enfermedad, con el consecuente impacto en el costo de salud ${ }^{11,12}$.

Durante los años 2009 y 2010 se desarrolló en Chile la segunda Encuesta Nacional de Salud
(ENS), cuya primera versión fue realizada el año 2003. La ENS 2009-2010, constituía una inmejorable oportunidad para determinar los rangos de referencia de TSH para nuestra población y poder así determinar la prevalencia de enfermedad funcional tiroidea ${ }^{13}$, por lo que a diferencia de lo ocurrido en 2003, se logró esta vez conseguir recursos para incluir la medición de TSH en dicho estudio.

\section{Pacientes y Métodos}

La ENS 2009-2010 es un estudio de prevalencia (transversal) nacional en hogares. La muestra de 5.412 personas adultas de 15 o más años es representativa de la población general chilena (no consultante, no institucionalizada), de ambos sexos, zonas urbanas y rurales y todas las regiones de nuestro país. El estudio excluye sólo a personas menores a 15 años y mujeres embarazadas.

La muestra de hogares es aleatoria, multietápica, por conglomerados y estratificada por zona y región. Se sobre representó adicionalmente a adultos mayores, regiones distintas a la metropolitana y zonas rurales del norte para homogeneizar la precisión de los estimadores en estos grupos, aumentando la eficiencia de la muestra. Los factores de expansión utilizados en el análisis devuelven sus características originales a la muestra haciéndola representativa de adultos chilenos según las proyecciones a enero de 2010 del último Censo Nacional. Así, los resultados de un sujeto con factor de expansión igual a 300, pesan 10 veces menos que los de uno con factor de expansión 3.000.

El estudio se desarrolló en los hogares mediante la visita de un encuestador donde se seleccionó un adulto al azar al interior del hogar y se preguntó por antecedentes de salud general, diagnósticos médicos auto reportados y se aplicaron algunos cuestionarios de síntomas. En una segunda visita, una enfermera realizó mediciones antropométricas, presión arterial, pulso y toma de muestras de sangre y orina junto con la aplicación de cuestionarios específicos adicionales. De los 7.200 hogares seleccionados, $12 \%$ rechazó participar, y $16 \%$ no logró ser contactado. Todos los restantes accedieron a la visita de la enfermera y $95 \%$ de ellos aceptaron entregar una muestra de sangre y orina.

La medición de TSH se realizó en una submuestra aleatoria de 2.795 sujetos, representativa del país y de cada una de sus regiones, y 
cuyas características se describen en la Tabla 1; a esta población se le llamará en adelante "población total TSH".

El cuestionario de tiroides está detallado en la Tabla 2. Se consideró que el sujeto no tenía antecedente de patología tiroidea si no reportaba un diagnóstico médico personal de patología tiroidea ni tratamiento farmacológico en las últimas dos semanas. A este grupo lo llamaremos en adelante "población sin antecedentes".

Con el fin de comparar nuestros resultados con NHANESIII generamos un tercer grupo de análisis denominado "población de referencia de laboratorio". Este grupo se genera considerando los sujetos de la población "sin antecedentes", ex- cluyendo todos los individuos cuya TSH estuviera por sobre o debajo del rango de referencia del kit de laboratorio utilizado (Figura 1).

Para la determinación de TSH se utilizó muestras de suero que fueron analizadas en forma centralizada por un único laboratorio (laboratorio central de la Pontificia Universidad Católica de Chile en Santiago) a través del ensayo electroquimioluminiscente de ROCHE cuya sensibilidad funcional es de $0,014 \mu \mathrm{UI} / \mathrm{mL}$, y cuyo margen de normalidad es de 0,3 a $4,2 \mu \mathrm{UI} / \mathrm{mL}$. El coeficiente de variación analítico interensayo es de 2,20\% para concentraciones de $0,66 \mathrm{uUI} / \mathrm{mL}$ y de $1,99 \%$ para valores de 6,75 uUI/mL.

Según las normas internacionales, el hiperti-

Tabla 1. Características demográficas de la población ENS 2009-2010 y la submuestra con determinación de TSH. Chile 2009-2010

\begin{tabular}{|c|c|c|c|c|c|c|}
\hline \multirow[b]{2}{*}{ Variable } & \multicolumn{3}{|c|}{ Total ENS 2009-2010 } & \multicolumn{3}{|c|}{ Total TSH } \\
\hline & $\mathbf{n}$ & $\%$ o media & IC $95 \%$ & $\mathbf{n}$ & $\%$ o media & IC $95 \%$ \\
\hline \multicolumn{7}{|l|}{ Sexo } \\
\hline Femenino & 3.168 & 51,3 & $49,0-53,6$ & 1.617 & 51,5 & $48,2-54,8$ \\
\hline \multicolumn{7}{|c|}{ Edad (años) } \\
\hline 15 a 24 & 803 & 21,8 & $19,9-23,7$ & 405 & 21,9 & $19,3-24,7$ \\
\hline 25 a 44 & 1.738 & 37,6 & $35,3-40,0$ & 906 & 38,5 & $35,3-41,9$ \\
\hline 45 a 64 & 1.757 & 28,6 & $26,6-30,6$ & 892 & 27 & $24,3-30,0$ \\
\hline 65 y más & 1.042 & 12,0 & $10,8-13,3$ & 550 & 12,5 & $10,8-14,5$ \\
\hline \multicolumn{7}{|l|}{ Zona } \\
\hline Urbana & 4.548 & 87,0 & $85,6-88,2$ & 2.384 & 89,9 & $88,3-91,2$ \\
\hline Rural & 790 & 13,0 & $11,8-14,4$ & 369 & 10,1 & $8,8-11,7$ \\
\hline \multicolumn{7}{|l|}{ Región } \\
\hline$X V$ & 311 & 1,2 & $1,0-1,4$ & 164 & 1,3 & $1,1-1,6$ \\
\hline 1 & 317 & 1,3 & $1,1-1,6$ & 171 & 1,5 & $1,2-2,0$ \\
\hline ॥ & 305 & 3,0 & $2,6-3,4$ & 157 & 3 & $2,5-3,6$ \\
\hline III & 315 & 1,8 & $1,6-2,1$ & 169 & 1,8 & $1,5-2,2$ \\
\hline IV & 306 & 4,5 & $3,9-5,2$ & 138 & 3,5 & $2,8-4,3$ \\
\hline V & 345 & 10,3 & $9,0-11,8$ & 131 & 8,3 & $6,6-10,3$ \\
\hline RM & 916 & 40,5 & $38,1-43,0$ & 449 & 40,4 & $37,0-43,9$ \\
\hline $\mathrm{VI}$ & 314 & 5,0 & $4,2-6,0$ & 140 & 4,1 & $3,2-5,3$ \\
\hline VII & 355 & 6,1 & $5,4-7,0$ & 227 & 7,8 & $6,6-9,2$ \\
\hline VIII & 293 & 11,9 & $10,3-13,8$ & 166 & 13,5 & $11,1-16,4$ \\
\hline IX & 331 & 6,0 & $5,2-7,0$ & 164 & 5,6 & $4,5-6,9$ \\
\hline XIV & 300 & 2,0 & $1,7-2,4$ & 168 & 2,2 & $1,8-2,7$ \\
\hline$x$ & 318 & 4,3 & $3,7-4,9$ & 193 & 4,9 & $4,0-6,0$ \\
\hline$X I$ & 299 & 0,7 & $0,6-0,8$ & 140 & 0,6 & $0,5-0,8$ \\
\hline XII & 315 & 1,3 & $1,0-1,5$ & 176 & 1,5 & $1,2-1,9$ \\
\hline
\end{tabular}

*La submuestra de TSH tiene un porcentaje significativamente mayor de población urbana que la ENS 2009-2010. IC 95\% = intervalo de $95 \%$ de confianza. 


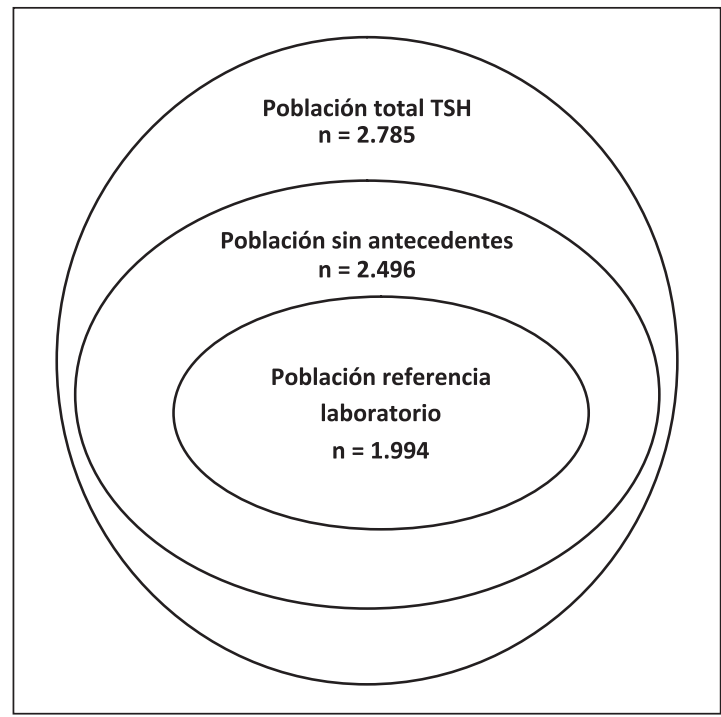

Figura 1. Relación entre población total TSH, población sin antecedentes y población de referencia laboratorio.

roidismo queda definido operacionalmente como aquellos sujetos con TSH bajo el percentil 2,5 de la población; y el hipotiroidismo, por aquellos sujetos con TSH superior al percentil 97,5. Dado que está en discusión la definición de "población sana" para establecer estos límites, en nuestro estudio se calcularon estos percentiles para las tres subpoblaciones detalladas anteriormente. Se presenta la mediana de TSH, y los percentiles 2,5 y 97,5 separados por sexo y grupos etarios.

Para el cálculo de percentiles, se excluyeron los sujetos con valores de TSH considerados como outliers matemáticos ( 3 veces la caja intercuartil, $\mathrm{TSH}>10,29 \mathrm{uUI} / \mathrm{mL}$ ). Sin embargo, los reportes de prevalencia de patología funcional tiroidea incluyen a todos los sujetos.

$\mathrm{Al}$ determinar los percentiles, cuando no se obtuvo exactamente el percentil buscado, se promediaron los dos valores más cercanos.

Los resultados se presentan con sus valores expandidos, representativos de la población general chilena.

\section{Resultados}

La población general chilena reporta 5,6\% de antecedentes personales de patología tiroidea y $11,5 \%$ de antecedente familiar. En cuanto a cáncer tiroideo, $0,3 \%$ reporta antecedente personal y
2,7\% antecedente familiar. El 2,7\% de los adultos chilenos reportan estar recibiendo fármacos por patología tiroidea (Tabla 2). Este último dato es coincidente con el análisis del módulo de medicamentos en uso actual de ENS 2009 (dato no en tabla), ya que la enfermera pudo constatar que el 2,8\% de los adultos chilenos se encontraban recibiendo levotiroxina de sodio.

Los sujetos de la submuestra de TSH son representativos de la muestra total ENS en cuanto a sus antecedentes de enfermedad tiroidea (Tabla 2) y en todos los factores poblacionales, a excepción de zona urbana/rural, dado que existe una mayor proporción de sujetos de zonas urbanas en la submuestra con TSH (Tabla 1).

En la muestra de población total con TSH medida $(n=2785), 299$ sujetos reportaron enfermedad personal tiroidea, por lo que la población "sin antecedentes" personales de enfermedad tiroidea se reduce a 2.496 participantes. De éstos, 502 presentaban rangos de hipotiroidismo o hipertiroidismo según el valor proporcionado por el kit de laboratorio; al excluirlos la muestra se reduce a 1.994 pacientes que constituyen nuestra tercera población de estudio llamada "referencia de laboratorio" (Figura 1).

En la Tabla 3b, se observa que, para ambos sexos, el percentil 97,5 aumenta conforme aumenta la edad. Este fenómeno es menos claro en la población total ENS (Tabla 3a) y desaparece en la población de referencia de laboratorio (Tabla 3c).

La prevalencia de hipertiroidismo e hipotiroidismo para las tres poblaciones consideradas presenta valores mayores en mujeres y a mayor edad (Tabla 4 y 5, respectivamente). Estas tendencias son más puras en la población sin antecedentes tiroideos.

\section{Discusión}

Este es el primer estudio epidemiológico de patología tiroidea representativo de la población chilena. La población sin antecedentes de enfermedad tiroidea tiene un percentil 97,5 para TSH más alto que lo publicado para otras poblaciones como la norteamericana de NHANES $^{3}$, diferencia que es más marcada en los estratos de población joven y desaparece en los mayores de 60 años (Figura 2). Sin embargo, la población "sin antecedentes" del estudio norteamericano excluía adicionalmente a personas con AcTPO positivos. 
Tabla 2. Cuestionario sobre antecedentes de enfermedad tiroidea personal y familiar aplicado en la ENS 2009-2010. Resultados en la población total ENS 2009-10 y en la submuestra con determinación de TSH

\begin{tabular}{|c|c|c|c|c|c|c|}
\hline & \multicolumn{3}{|c|}{ ENS 2009-10 } & \multicolumn{3}{|c|}{ Submuestra TSH } \\
\hline & $\mathbf{n}$ & $\begin{array}{c}\% \text { o } \\
\text { media }\end{array}$ & IC $95 \%$ & $\mathbf{n}$ & $\begin{array}{c}\% \text { o } \\
\text { media }\end{array}$ & IC $95 \%$ \\
\hline $\begin{array}{l}\text { En su familia directa (hijos, padre, madre o hermanos), } \\
\text { ¿alguien ha enfermado o muerto de cáncer de tiroides? } \\
\text { (\% Sí) }\end{array}$ & 5.118 & 2,7 & $2,0-3,7$ & 2.646 & 3,2 & $2,1-5,0$ \\
\hline $\begin{array}{l}\text { En su familia directa (hijos, padre, madre o hermanos), } \\
\text { ¿alguien ha enfermado o muerto de bocio o enferme- } \\
\text { dad a la tiroides? (\% Sí) }\end{array}$ & 5.135 & 11,5 & $10,1-13,1$ & 2.643 & 11,7 & $9,6-14,1$ \\
\hline $\begin{array}{l}\text { ¿Alguna vez un doctor o médico le ha dicho que tiene } \\
\text { o padece de bocio, enfermedad a la tiroides hipertoroi- } \\
\text { dismo o hipotiroidismo? (\% Sí) }\end{array}$ & 4.958 & 5,6 & $4,7-6,7$ & 2.746 & 5,0 & $3,9-6,5$ \\
\hline ¿A qué edad (años) se lo diagnosticaron? & 315 & 37,45 & $34,1-40,8$ & 155 & 37,65 & $33,1-42,2$ \\
\hline ¿Alguna vez ha sido tratado por esto? (\% Sí) & 4.974 & 4,6 & $3,8-5,6$ & 2.753 & 4,3 & $3,3-5,7$ \\
\hline $\begin{array}{l}\text { ¿Ha estado tomando algún medicamento o haciendo } \\
\text { algún tratamiento para esto durante las últimas dos } \\
\text { semanas? (\% Sí) }\end{array}$ & 4.977 & 2,7 & $2,2-3,4$ & 2754 & 2,7 & $1,9-3,8$ \\
\hline $\begin{array}{l}\text { ¿Alguna vez un doctor o médico le ha dicho que tiene } \\
\text { o padece de cáncer de tiroides? (\% Sí) }\end{array}$ & 4.930 & 0,3 & $0,1-0,7$ & 2.737 & 0,3 & $0,1-1,1$ \\
\hline ¿A qué edad (años) se lo diagnosticaron? & 11 & 44,3 & $35,3-53,4$ & 5 & 41,9 & $35,3-48,6$ \\
\hline ¿Alguna vez ha sido tratado por esto? (\% Sí) & 4.979 & 0,7 & $0,4-1,2$ & 2.755 & 0,6 & $0,3-1,4$ \\
\hline $\begin{array}{l}\text { ¿Ha estado tomando algún medicamento o haciendo } \\
\text { algún tratamiento para esto durante las últimas dos } \\
\text { semanas? (\% Sí) }\end{array}$ & 4.954 & 0,4 & $0,2-0,8$ & 2.754 & 0,4 & $0,1-1,1$ \\
\hline
\end{tabular}

Tabla 3. Medianas y percentiles 2,5 y 97,5 de TSH ( $\mu \mathrm{Ul} / \mathrm{ml})$ en población total de TSH (a), sin antecedentes tiroideos (b) y de referencia de laboratorio (c). ENS 2009-2010, Chile

\section{Tabla 3a}

\begin{tabular}{|c|c|c|c|c|c|c|c|c|c|}
\hline \multirow[b]{2}{*}{ Edad } & \multirow{2}{*}{\multicolumn{2}{|c|}{$\begin{array}{l}\text { Masculino } \\
\text { med }\end{array}$}} & \multirow[b]{2}{*}{ p 97,5} & \multicolumn{3}{|c|}{$\begin{array}{l}\text { Población total de TSH } \\
\text { Femenino }\end{array}$} & \multicolumn{3}{|c|}{ Ambos géneros } \\
\hline & & & & p 2,5 & med & p 97,5 & p 2,5 & med & p 97,5 \\
\hline $15-19$ & 0,71 & 2,66 & 7,32 & 0,76 & 2,24 & 5,43 & 0,81 & 2,47 & 6,26 \\
\hline $20-29$ & 0,96 & 2,43 & 6,71 & 0,69 & 2,31 & 7,18 & 0,96 & 2,37 & 7,01 \\
\hline $30-39$ & 1,02 & 2,45 & 8,64 & 0,17 & 3,05 & 7,40 & 0,37 & 2,74 & 8,26 \\
\hline $40-49$ & 0,67 & 2,16 & 7,41 & 0,28 & 2,39 & 10,62 & 0,54 & 2,25 & 10,71 \\
\hline $50-59$ & 0,91 & 2,97 & 18,71 & 0,34 & 2,81 & 10,78 & 0,74 & 2,92 & 10,78 \\
\hline $60-69$ & 0,46 & 2,13 & 9,05 & 0,55 & 3,04 & 14,56 & 0,52 & 2,44 & 12,97 \\
\hline $70-79$ & 0,83 & 2,35 & 6,61 & 0,20 & 3,02 & 9,69 & 0,20 & 2,99 & 9,37 \\
\hline 80 y más & 0,29 & 4,11 & 7,52 & 0,50 & 3,07 & 9,67 & 0,53 & 3,84 & 9,67 \\
\hline Total & 0,72 & 2,43 & 8,34 & 0,52 & 2,61 & 10,2 & 0,59 & 2,52 & 9,71 \\
\hline
\end{tabular}


Tabla 3b

\begin{tabular}{|c|c|c|c|c|c|c|c|c|c|}
\hline \multirow[b]{3}{*}{ Edad } & \multirow{3}{*}{\multicolumn{2}{|c|}{$\begin{array}{l}\text { Masculino } \\
\text { med }\end{array}$}} & \multicolumn{5}{|c|}{ Población sin antecedentes tiroideos } & & \\
\hline & & & & & emenin & & \multicolumn{3}{|c|}{ Ambos géneros } \\
\hline & & & p 97,5 & p 2,5 & med & p 97,5 & p 2,5 & med & p 97,5 \\
\hline $15-19$ & 0,95 & 2,66 & 6,09 & 0,76 & 2,24 & 5,43 & 0,85 & 2,49 & 6,21 \\
\hline $20-29$ & 0,96 & 2,36 & 5,97 & 0,69 & 2,23 & 7,01 & 0,96 & 2,31 & 6,57 \\
\hline 30-39 & 1,02 & 2,43 & 6,22 & 0,37 & 3,05 & 6,35 & 0,66 & 2,74 & 6,22 \\
\hline $40-49$ & 0,67 & 2,13 & 6,49 & 0,77 & 2,39 & 8,16 & 0,72 & 2,23 & 7,99 \\
\hline 50-59 & 0,91 & 2,85 & 6,13 & 0,72 & 2,82 & 7,74 & 0,90 & 2,92 & 6,96 \\
\hline $60-69$ & 0,54 & 2,13 & 8,80 & 0,83 & 2,95 & 7,41 & 0,71 & 2,35 & 7,69 \\
\hline 70-79 & 0,95 & 2,35 & 6,55 & 0,49 & 3,02 & 8,49 & 0,87 & 2,99 & 7,87 \\
\hline 80 y más & 0,29 & 4,08 & 7,52 & 0,92 & 3,78 & 9,67 & 0,52 & 4,04 & 9,67 \\
\hline Total & 0,86 & 2,40 & 6,98 & 0,79 & 2,61 & 7,98 & 0,83 & 2,50 & 7,46 \\
\hline
\end{tabular}

Tabla 3c

\begin{tabular}{|lcccccccc|c|}
\hline & & & \multicolumn{4}{c}{ Población referencia de laboratorio } & \multicolumn{3}{c|}{ Ambos géneros } \\
Edad & $\mathbf{p ~ 2 , 5}$ & $\begin{array}{c}\text { Masculino } \\
\text { med }\end{array}$ & $\mathbf{p ~ 9 7 , 5}$ & $\mathbf{p ~ 2 , 5}$ & $\begin{array}{c}\text { Femenino } \\
\text { med }\end{array}$ & $\mathbf{p ~ 9 7 , 5}$ & $\mathbf{p ~ 2 , 5}$ & med & $\mathbf{p}, \mathbf{5}$ \\
$15-19$ & 0,95 & 2,58 & 5,13 & 0,84 & 2,16 & 4,70 & 0,92 & 2,41 & 4,99 \\
\hline $20-29$ & 0,96 & 2,09 & 3,99 & 0,69 & 2,05 & 4,02 & 0,85 & 2,10 & 4,02 \\
\hline $30-39$ & 1,02 & 2,28 & 3,89 & 0,81 & 2,64 & 4,16 & 0,88 & 2,35 & 4,16 \\
\hline $40-49$ & 0,67 & 2,03 & 3,67 & 0,67 & 2,06 & 3,81 & 0,72 & 2,04 & 3,68 \\
\hline $50-59$ & 0,91 & 2,42 & 4,15 & 0,72 & 2,32 & 4,07 & 0,80 & 2,35 & 4,14 \\
\hline $60-69$ & 0,54 & 1,58 & 3,81 & 0,83 & 2,24 & 3,95 & 0,68 & 2,04 & 3,95 \\
\hline $70-79$ & 0,95 & 2,10 & 4,12 & 0,95 & 2,91 & 3,48 & 0,95 & 2,45 & 3,99 \\
\hline 80 y más & $0,54 *$ & 2,02 & 3,96 & 0,92 & 1,85 & 3,95 & 0,52 & 1,87 & 4,04 \\
\hline Total & 0,765 & 2.135 & 4,07 & 0,84 & 2,20 & 4,16 & 0,82 & 2,17 & 4,13 \\
\hline
\end{tabular}

Med $=$ medianas; p 2,5 = percentil 2,5; p 97,5 = percentil 97,5.

Tabla 4. Prevalencias de hipertiroidismo (\%) según género y grupo etario, calculado de acuerdo a percentil 2,5 en diferentes subpoblaciones, ENS 2009-10

\begin{tabular}{|c|c|c|c|c|c|c|c|c|c|}
\hline \multirow[b]{2}{*}{ Edad } & \multirow[b]{2}{*}{ PT } & \multicolumn{2}{|c|}{ Masculino } & \multirow[b]{2}{*}{ PT } & \multicolumn{2}{|c|}{ Femenino } & \multirow[b]{2}{*}{ PT } & \multicolumn{2}{|c|}{ Ambos sexos } \\
\hline & & PSA & PRL & & PSA & PRL & & PSA & PRL \\
\hline $15-19$ & 3,0 & 3,04 & 3,40 & 1,8 & 4,45 & 5,37 & 2,4 & 3,73 & 4,37 \\
\hline $20-29$ & 1,1 & 1,49 & 1,08 & 0,4 & 2,67 & 2,67 & 0,8 & 2,05 & 1,83 \\
\hline $30-39$ & 1,5 & 1,74 & 1,74 & 4,0 & 4,66 & 4,54 & 1,5 & 3,12 & 3,06 \\
\hline $40-49$ & 1,6 & 4,74 & 1,84 & 3,9 & 4,93 & 4,89 & 2,9 & 4,85 & 3,59 \\
\hline $50-59$ & 0,4 & 0,48 & 0,48 & 3,2 & 4,40 & 4,40 & 3,6 & 2,42 & 2,42 \\
\hline $60-69$ & 5,4 & 5,92 & 5,78 & 1,8 & 6,75 & 4,82 & 3,5 & 6,36 & 5,27 \\
\hline $70-79$ & 1,0 & 2,10 & 0,96 & 6,2 & 6,96 & 6,96 & 3,8 & 4,78 & 4,28 \\
\hline 80 y más & 7,7 & 7,70 & 7,70 & 2,8 & 12,72 & 12,72 & 4,9 & 10,59 & 10,59 \\
\hline Total & 2,0 & 2,82 & 2,19 & 2,8 & 4,93 & 4,78 & 2,4 & 3,89 & 3,51 \\
\hline
\end{tabular}

(1) PT: población total de TSH. (2) PSA: población sin antecedentes tiroideos. (3) PRL: población referencia de laboratorio. 
Tabla 5. Prevalencias de hipotiroidismo según género y grupo etario según percentil 97,5 extraído de diferentes subpoblaciones, ENS 2009-10

\begin{tabular}{|c|c|c|c|c|c|c|c|c|c|}
\hline \multirow[b]{2}{*}{ Edad } & \multirow[b]{2}{*}{ PT } & \multicolumn{2}{|c|}{ Masculino } & \multirow[b]{2}{*}{ PT } & \multicolumn{2}{|c|}{ Femenino } & \multirow[b]{2}{*}{ PT } & \multicolumn{2}{|c|}{ Ambos sexos } \\
\hline & & PSA & PRL & & PSA & PRL & & PSA & PRL \\
\hline $15-19$ & 2,8 & 5,23 & 9,10 & 2,2 & 2,23 & 4,79 & 2,5 & 3,76 & 6,98 \\
\hline $20-29$ & 1,7 & 2,04 & 15,48 & 0,5 & 2,15 & 18,08 & 1,2 & 2,09 & 16,71 \\
\hline $30-39$ & 1,9 & 3,55 & 22,00 & 1,0 & 2,52 & 30,03 & 1,5 & 3,07 & 25,78 \\
\hline $40-49$ & 2,3 & 2,54 & 9,66 & 4,3 & 8,37 & 23,81 & 3,5 & 5,88 & 17,76 \\
\hline $50-59$ & 3,2 & 4,19 & 32,98 & 4,0 & 5,84 & 32,34 & 3,6 & 5,00 & 32,66 \\
\hline $60-69$ & 0,8 & 3,51 & 26,72 & 8,3 & 12,25 & 29,67 & 4,7 & 8,12 & 28,27 \\
\hline $70-79$ & 0,9 & 1,73 & 17,96 & 1,8 & 11,58 & 31,63 & 1,4 & 7,18 & 25,52 \\
\hline 80 y más & - & 18,61 & 65,05 & 1,3 & 9,07 & 35,57 & 0,7 & 13,11 & 48,06 \\
\hline Total & 2,01 & 3,61 & 19,77 & 3,1 & 5,98 & 24,24 & 2,5 & 4,82 & 22,05 \\
\hline
\end{tabular}

(1) PT: población total de TSH. (2) PSA: población sin antecedentes. (3) PRL: población referencia de laboratorio.

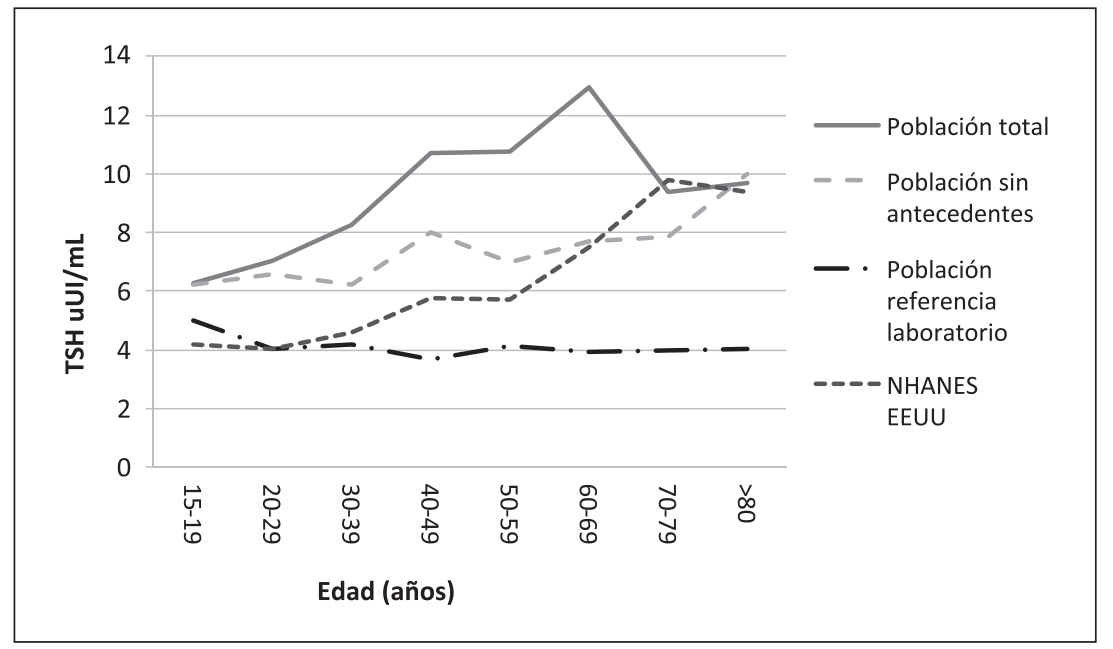

Figura 2. Percentil $97,5 \mathrm{TSH}$ para los diferentes rangos de edad en las diferentes subpoblaciones de la ENS 2009-2010 Chile y en población libre de enfermedad en NHANES III, Estados Unidos de Norteamérica.
Este hallazgo obliga a analizar con más detalle si efectivamente tenemos más hipotiroidismo en Chile o si sólo nuestro punto de corte de TSH debiera ser superior al reportado por nuestro laboratorio.

Nuestra población y la norteamericana tampoco son estrictamente comparables en lo referente a otras variables que pueden afectar la distribución de TSH (nivel educacional, índice de masa corporal, presencia de dislipidemia, etc) ${ }^{13-16}$, por lo cual es razonable hacer esfuerzos por generar puntos de corte locales ${ }^{8}$.

Es especialmente notoria la gran diferencia que hemos encontrado en Chile entre el percentil
97,5 de la población sin antecedentes tiroideos en comparación con el valor máximo de normalidad en el kit de laboratorio, lo que nos hace suponer que el punto de corte chileno puede ser realmente superior al del kit. Por otra parte, el uso de los cortes del kit genera una homogeneización de las medianas por edad y sexo que no parece fisiológicamente razonable.

Al aplicar el percentil 97,5 de nuestra población sin antecedentes, sólo 4,82\% de la población tendría hipotiroidismo, valor que es mucho más cercano a los reportes internacionales e implicaría aproximadamente una cobertura actual de tratamiento con levotiroxina de sodio de $58 \%$. Por el 
contrario, si aplicamos el valor máximo de referencia del kit de laboratorio deberíamos aceptar una prevalencia de hipotiroidismo de $22,05 \%$ en Chile, lo que es alarmante y tiene efectos complejos para las políticas de salud ya que implicaría que la cobertura de tratamiento actual del sistema, no superaría el $12 \%$.

En el informe técnico de la ENS se reportó una mayor prevalencia de hipotiroidismo en la población con nivel educacional más bajo, lo que merece mayor estudio en Chile. Es posible que esto se encuentre explicado por la mayor prevalencia de obesidad, factores dietéticos o ambientales ${ }^{13}$.

Los métodos de laboratorio para determinar TSH más utilizados mundialmente son los de Nichols, Delfia y Roche. Cabe destacar que la NHANES utilizó el $k i t$ Nichols $^{3}$, el estudio HUNT de Finlandia utilizó el kit Delfia ${ }^{4}$ y nuestro estudio el kit Roche ${ }^{13}$.

Los fabricantes de kits de laboratorio deben cumplir con las normas de la NACB, que exige determinar el valor normal en al menos 120 sujetos voluntarios sanos, eutiroideos, sin anticuerpos antitiroideos, sin historia familiar ni personal de disfunción tiroidea ni bocio y sin uso de fármacos que pudieran interferir con la tiroides, con un intervalo de confianza de $95 \%{ }^{2}$. Esta población no es representativa de la población general.

Se ha planteado que para establecer una población de referencia adecuada en patología tiroidea funcional, se debiese excluir a aquellos sujetos con presencia de AcTPO. Este es un análisis pendiente a realizar en ENS 2009, junto a la exploración del comportamiento de las medianas de TSH al excluir adicionalmente a estos sujetos positivos de la población "sin antecedentes". Sin embargo, el incluir este requisito en la definición de una población "sana" puede ser debatible ${ }^{17,18}$. La medición de AcTPO a nivel poblacional en estudios de cohorte ha demostrado ser un predictor significativo de riesgo individual de patología funcional tiroidea futura; sin embargo, su impacto poblacional es bajo ya que cerca del $60 \%$ de las personas con anticuerpos seguidas a 20 años no desarrollan

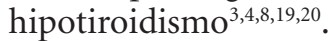

La elección del método más válido para establecer valores normales de laboratorio en salud es hoy un tema de creciente debate. Las alternativas fundamentales son dos. En primer lugar se encuentra el criterio estadístico, basado en la distribución y percentiles observados en una población "sana", sin embargo, este método tiene cada día más dificultades en el campo de las enfermedades crónicas ya que la multimorbilidad por estas patologías en la población general es tan alta, que la población "sana" es una minoría. Por otra parte, esta alternativa requiere de estudios locales, con puntos de corte diferenciales en distintas comunidades. En el presente estudio, se intenta avanzar en este esfuerzo, sin embargo, existe aun una segunda alternativa completamente diferente y ligada a la salud pública y los criterios de costo efectividad. Por ejemplo, se podría pensar en establecer aquel punto de corte de TSH que identifique el valor sobre el cual el tratamiento disponible le significa al paciente un beneficio en riesgo cardiovascular o calidad de vida. Es así como, por ejemplo, hay estudios que muestran que en población mayor a 85 años el hipotiroidismo subclínico puede tener un efecto protector ${ }^{21}, \mathrm{u}$ otros estudios que muestran que sobretratar a adultos mayores con hormona tiroidea no sería conveniente por el aumento del riesgo de fracturas osteoporóticas ${ }^{22}$.

En conclusión, este es el primer estudio que analiza la normalidad de los valores de TSH en Chile. A la luz de nuestros resultados se abre la perspectiva de ampliar el rango de normalidad de TSH, evitando así el sobre diagnóstico de hipotiroidismo subclínico. Aún no podemos definir con evidencia suficiente un punto de referencia para TSH que sea aplicable a nuestra población general, pero esperamos que en el futuro podremos aportar más evidencia en este sentido y poder establecer puntos de corte locales, por edad y sexo.

Agradecimientos: La ENS 2009-2010 fue financiada por el MINSAL y ejecutada por el Departamento de Salud Pública de la Pontificia Universidad Católica de Chile (PUC). La PUC recibió un aporte irrestricto y directo de Laboratorio Merk S. A. para financiar la medición de TSH en la ENS.

\section{Referencias}

1. Ichihara K, Boyd JC. An appraisal of statistical procedures used in derivation of reference intervals. Clin Chem Lab Med: CCLM/FESCC. 2010; 48 (11): 1537-51.

2. Baloch Z, Conte-Devoix B, Demers L, Feldt-Rasmussen U, Henry J-F, et al. Laboratory medicine practice guidelines - Laboratory support for the diagnosis and moni- 
toring of thyroid disease. Thyroid 2003; 13 (1): 3-126.

3. Hollowell JG. Serum TSH, T4, and Thyroid Antibodies in the United States Population (1988 to 1994): National Health and Nutrition Examination Survey (NHANES III). J Clin Endocrinol Metab 2002; 87 (2): 489-99.

4. Bjoro T, Holmen J, Krüger O, Midthjell K, Hunstad K, Schreiner T, et al. Prevalence of thyroid disease, thyroid dysfunction and thyroid peroxidase antibodies in a large, unselected population. The Health Study of NordTrondelag (HUNT). European J Endocrinol 2000; 143 (5): 639-47.

5. Vejbjerg P, Knudsen N, Perrild H, Laurberg P, Pedersen IB, Rasmussen LB, et al. The association between hypoechogenicity or irregular echo pattern at thyroid ultrasonography and thyroid function in the general population. European J Endocrinol 2006; 155(4): 547 52.

6. Kratzsch J, Fiedler GM, Leichtle A, Brügel M, Buchbinder S, Otto L, et al. New reference intervals for thyrotropin and thyroid hormones based on National Academy of Clinical Biochemistry criteria and regular ultrasonography of the thyroid. Clin Chem 2005; 51 (8): 1480-6.

7. Völzke H, Alte D, Kohlmann T, Lüdemann J, Nauck $\mathrm{M}$, John U, et al. Reference intervals of serum thyroid function tests in a previously iodine-deficient area. Thyroid 2005; 15 (3): 279-85.

8. Boucai L, Hollowell JG, Surks MI. An approach for development of age-, gender-, and ethnicity-specific thyrotropin reference limits. Thyroid 2011; 21 (1): 5-11.

9. Boucai L, Surks MI. Reference limits of serum TSH and free T4 are significantly influenced by race and age in an urban outpatient medical practice. Clin Endocrinol 2009; 70 (5): 788-93.

10. Surks MI, Boucai L. Age- and race-based serum thyrotropin reference limits. J Clin Endocrinol Metab 2010; 95 (2): 496-502.

11. Surks M, Ortiz E, Daniels GH, Sawin CT, Cobin RH, Franklyn JA, et al. Subclinical Thyroid Disease. JAMA. 2004; 291 (2): 228-38.

12. Surks MI, Goswami G, Daniels GH. The thyrotropin reference range should remain unchanged. J Clin Endocrinol Metab 2005; 90 (9): 5489-96.

13. Encuesta nacional de salud Chile 2009-2010 [Internet]. 2010;Available from: http://www.encuestasalud.cl/ens/
wp-ontent/uploads/2011/09/InformeENS_2009-2010_ CAP5.pdf

14. Knudsen N, Laurberg P, Rasmussen LB, Bülow I, Perrild $\mathrm{H}$, Ovesen L, et al. Small differences in thyroid function may be important for body mass index and the occurrence of obesity in the population. J Clin Endocrinol Metab 2005; 90 (7): 4019-24.

15. Asvold BO, Vatten LJ, Nilsen TIL, Bjøro T. The association between TSH within the reference range and serum lipid concentrations in a population-based study. The HUNT Study. European J Endocrinol 2007; 156 (2): 181-6.

16. Canaris GJ, Manowitz NR, Mayor G, Ridgway EC. The Colorado thyroid disease prevalence study. Arch Inter Med 2000; 160 (4): 526-34.

17. Takeda K, Mishiba M, Sugiura H, Nakajima A, Kohama $\mathrm{M}$, Hiramatsu S. Evaluated reference intervals for serum free thyroxine and thyrotropin using the conventional outliner rejection test without regard to presence of thyroid antibodies and prevalence of thyroid dysfunction in Japanese subjects. Endocrine J 2009; 56 (9): 1059-66.

18. Kratzsch J, Schubert G, Pulzer F, Pfaeffle R, Koerner A, Dietz A, et al. Reference intervals for TSH and thyroid hormones are mainly affected by age, body mass index and number of blood leucocytes, but hardly by gender and thyroid autoantibodies during the first decades of life. Clin biochem 2008; 41 (13): 1091-8.

19. Vanderpump MP, Tunbridge WM, French JM, Appleton D, Bates D, Clark F, et al. The incidence of thyroid disorders in the community: a twenty-year follow-up of the Whickham Survey. Clin Endocrinol 1995; 43 (1): 55-68.

20. Walsh JP, Bremner AP, Feddema P, Leedman PJ, Brown SJ, O'Leary P. Thyrotropin and thyroid antibodies as predictors of hypothyroidism: a 13-year, longitudinal study of a community-based cohort using current immunoassay techniques. The Journal of clinical endocrinology and metabolism 2010; 95 (3): 1095-104.

21. Mariotti S, Cambuli VM. Cardiovascular risk in elderly hypothyroid patients. Thyroid 2007; 17 (11): 1067-73.

22. Turner MR, Camacho X, Fischer HD, Austin PC, Anderson GM, Rochon PA, et al. Levothyroxine dose and risk of fractures in older adults: nested case-control study. BMJ 2011; 342: d2238-d2238. 